\title{
Unmet Needs of Male Caregivers of Children and Youth with Special Health Care Needs
}

\author{
Allyson Lynch ${ }^{1,2} \cdot$ Valerie Raziano $^{1} \cdot$ Katie Feehan ${ }^{3} \cdot$ Eileen Thompson $^{4} \cdot$ Philip Massey $^{1} \cdot$ Renee Turchi $^{1,2,3,4,5}$ (i)
}

Accepted: 30 September 2021 / Published online: 15 October 2021

(c) The Author(s), under exclusive licence to Springer Science+Business Media, LLC, part of Springer Nature 2021

\begin{abstract}
Objectives The caregiving experiences and unique health needs of male caregivers of children and youth with special health care needs (CYSHCN) are not well described. This study seeks to understand potential unmet health needs and attitudes toward supportive resources from the perspective of a sample of male caregivers of CYSHCN.

Methods This mixed-methods study recruited a convenience sample of 30 men with CYSHCN who receive care for a chronic medical condition from primary care medical homes in Pennsylvania. We conducted semi-structured interviews (SSI), administered quantitative surveys to caregivers, and produced a thematic analysis. The SSI explored the health needs of male caregivers, assessed attitudes toward and preferences regarding supportive resources, and garnered their advice to other caregivers regarding parenting and health care system navigation.

Results Participants' median age is 41 years (IQR: 33, 44), and most (80\%) reside full time with their CYSHCN. Most male caregivers deprioritized their own emotional, mental, and physical health needs to support the needs of their families. Many male caregivers articulated interest in seeking emotionally supportive resources (not time-intensive). They advised other male caregivers to remain involved in the medical care and wellbeing of their CYSCHN and to openly seek and receive emotional support despite the daily challenges they face.

Conclusions for Practice Male caregivers of CYSHCN experience intense daily stress and express the need for emotionally supportive resources. Programs designed to facilitate such support may benefit from flexible formats (time and location) and involve male caregivers of CYSHCN as both facilitators and participants.
\end{abstract}

Keywords Children with special health care needs $\cdot$ Family centered care $\cdot$ Emotional support $\cdot$ Caregiver health $\cdot$ Social support $\cdot$ Male caregivers

\author{
Abbreviations \\ CYSHCN Children and youth with special health care \\ needs \\ CMC Children with medical complexity \\ SSI Semi-structured interviews
}

Renee Turchi

renee.turchi@towerhealth.org

1 Drexel University Dornsife School of Public Health, 3215 Market Street, Philadelphia, PA 19104, USA

2 Drexel University College of Medicine, 2900 West Queen Lane, Philadelphia, PA 19129, USA

3 St. Christopher's Hospital for Children, 160 East Erie Avenue, Philadelphia, PA 19134, USA

4 PA AAP, PA Medical Home Program, 1400 North Providence Road, Media, PA 19063, USA

5 Medical Director Center for CYSHCN, Department of Pediatrics, St. Christopher's Hospital for Children, 160 East Erie Avenue, Philadelphia, PA 19134, USA

\section{Significance}

What is already known on this subject? Parenting CYSHCN often requires intense engagement to maintain the health and wellbeing of their children. Positive paternal engagement strongly contributes to overall family functioning, yet the individual health needs and constraints of male caregivers of CYSHCN have been coarsely examined.

What this study adds? This work highlights unmet health needs of male caregivers of CYSHCN and the importance of improving their emotional support opportunities. Support 
options should be sensitive to time and location barriers while offering male caregivers spaces to give and receive support.

\section{Introduction}

National estimates indicate $19 \%$ of children have special health care needs (DRC Child/Adolescent Health, 2016; McPherson et al., 1998). Parenting children and youth with special health care needs (CYSHCN) requires intense caregiver engagement in a panoply of roles/responsibilities to maintain child health and wellbeing (Nicholas, 2017; Sato et al., 2018; Warfield, 2005). Role-related demands on time/ energy limit parental ability to fulfill needs external to their CYSHCN (health, work, family life). (Sellmaier, 2019; Woodgate et al., 2015). Child-related concerns of parents of CYSHCN span environmental, behavioral/cognitive domains and may be accompanied by feelings of exhaustion, stress, sleeplessness, anxiety, and depression (Bailey-Pearce et al., 2018; Baldwin et al., 2018; Chung et al., 2012; Hatzmann et al., 2008; Heaman, 1995; Kerstis et al., 2018; Kuo et al., 2011; Smith \& Grzywacz, 2014). Children with medical complexity (CMC) represent a medically fragile subset of CYSHCN (1\%) characterized by: health care service need (therapy, educational, medical), one/more chronic condition, functional limitation in bodily structure/performance of activities, and increased health care utilization. (Cohen et al., 2011). These foregone parental physical and mental health needs suggest male caregivers are a specific group who could benefit from increased connection to supportive resources (Caicedo, 2014; Cené et al., 2016; Feudtner, 2002; Keller \& Honig, 2004; Kobylianskii et al., 2018).

Despite the importance of positive paternal engagement in family functioning, there is a dearth of literature examining individual needs and constraints of male caregivers of CYSHCN in medical/non-medical contexts ( ; Baker et al., 2018; Tully et al., 2017). Understanding unique male caregiver needs provides support opportunities for improved functioning of individuals/family units. (Cohen et al., 2011; Tully et al., 2017). Documented stressors among male caregivers of CYSHCN reflect concerns about nurturing relationships/marriage, financial stability, and maintaining perceived control while facing persistent challenges (Bailey-Pearce et al., 2018; Heaman, 1995; Logan \& Dormire, 2018; Nicholas, 2017). As CYSHCN engage frequently with the health care system, providing family-centered care via shared decision-making is critical. (Cené et al., 2016; Kuo et al., 2011). Thus, understanding how male caregivers of CYSHCN describe their own needs and constraints can inform clinical environments to supportively engage families. The objective of this study was to elicit perspectives of male caregivers of CYSHCN, with an emphasis on ascertaining unmet personal needs, describing parenting experiences, and identifying supportive resources.

\section{Methods}

\section{Participants}

\section{Research Team}

One female medical/public health student [AL] conducted all interviews after receiving formative training in qualitative research methods, mentor support and informing participants of study goals. The interviewer had no affiliation with practice sites, participants were not aware of any additional biases/personal characteristics. The research team consisted of six members [AL, VR, PM, ET, RT, KF] including qualitative research experts, an interviewer, and data coders. They met regularly preparing for the study, recruitment discussing methodology, themes generated, coding reconciliation, and working with participant feedback to achieve consensus on themes, thematic saturation, and interpretation of findings. There was no prior treating relationship between any researcher except [RT], who was not engaged in recruitment/ consenting participants.

\section{Study Design}

A convenience sample was identified and recruited from a subsample $(\mathrm{n}=4)$ of the PA Medical Home Program (Mohanty et al., 2018) primary care practices in southeastern Pennsylvania. Geographic recruitment was limited to foster in-person connection of the interviewer to participants and limit variability of practice experience as a potential confounder. Three practices were urban children's hospital-based practices and one was a suburban satellite one of the hospitals. Potential participants were identified based on chart review by practice care coordinators. Participant inclusion criteria were self-identification as a father, stepfather, foster father, or other male caregiver of a CYSHCN receiving healthcare in a one of the study practices. English and Spanish-speaking caregivers were included. Potential participants were approached in-person or by phone by [KF] who had no prior relationship to participants to explain the purpose of the study and gauge initial interest. If participants indicated interest, $[\mathrm{AL} / \mathrm{KF}]$ reviewed additional details and obtained informed consent.

Stakeholders [RT, ET] who engage regularly with this study population initially met with research staff to share knowledge of potential population needs and to inform interview guide development. The interview guide was pilot tested with three caregivers, feedback obtained, reviewed by the research team and modifications made. Collaborators 
with qualitative research experience [PM, VR, RT] continued to refine the guide before usage with study participants. The finalized interview guide included thirteen open-ended questions exploring experiences of routine childcare, factors promoting resilience/success, those proving challenging for primary male caregivers, and advice to other caregivers (“Appendix").

Semi-structured interviews (SSI) were conducted inperson or by phone between February and June, 2018. [AL] conducted all interviews in English from a comfortable, private waiting room adjacent to primary care offices. Follow up questions and probes were given based on study responses. An interpreter was available for Spanish-speaking participants, all of whom interviewed in-person. Aside from the interpreter, no one else was present besides the participant and interviewer. Support from members of the research team and a social worker were available onsite/telephonically at all times if there were questions, concerns and queries about the study and/or research questions. After the SSI, in-person participants completed a survey to assess sociodemographic characteristics. Telephone participants completed the survey prior to the SSI. There were no repeat interviews.

All interviews were audio-recorded and transcribed verbatim by the interviewer. Spanish interviews were transcribed in Spanish and back translated into English by a certified interpreter. Field notes were taken during and after the interviews and discussed with the research team at regularly scheduled research team meetings. Subjects were recruited until thematic saturation was achieved. Transcripts and analyses were reviewed and discussed with the research team. Thematic results were discussed and fact checked with study participants. Written or verbal informed consent was given by all participants before their enrollment, and each received a $\$ 25$ grocery/retail store gift card upon completion of the study. This study was reviewed and approved by the Drexel University Institutional Review Board and performed in accordance with Declaration of Helsinki ethical standards and amendments. The authors followed the Consolidated Criteria for Reporting Qualitative Health Research (COREQ) criteria for reporting this research.

\section{Analysis}

After $80 \%$ of interviews were completed, a working codebook was developed by hand and preliminary thematic analysis was developed by two data coders and then discussed and reviewed by the research team. Themes from transcripts evolved from the data employing grounded theory. Additional participants were recruited until thematic saturation was achieved and discussed with the research team. Five paternal caregivers participated in codebook review and gave feedback on findings and themes generated.
Qualitative analysis software [N-VIVO 12 was used (QSR International)] to produce a secondary codebook incorporating themes of the primary analysis (QSR International Pty Ltd., 2019). We developed initial topical and inductive codes and definitions through open-coding of $20 \%$ of transcripts (Patton, 2005). The research team engaged in collaborative discussions to revise and finalize code definitions including co-coding of three transcripts to ensure consistency in code application and assure intercoder reliability. Regular group discussion of summaries and quotes informed data reduction, synthesis, interpretation, and grounded theory where themes were generated and discussed. Consensus was achieved across research team members. Data from quantitative surveys were entered into a secure, password-protected database. Descriptive characteristics were tabulated using SAS 9.4 (Cary, NC Inc., 2019; QSR International Pty Ltd., 2019).

\section{Results}

\section{Participant Characteristics (Table 1)}

Thirty of thirty-one (97\%) male caregivers approached chose to participate in the study. One participant declined enrollment due to CYSHCN hospitalization/medical complications arising at time of the study. Interview time ranged from 47 to $132 \mathrm{~min}$. The CYSHCN in this study represent children meeting the definition/framework for CMC with any increased service needs, dependence of medical technology, requiring home nursing services and/or intensive care coordination. Specific diagnostic information on the sample was not included or linked to transcripts or quotes to preserve anonymity. Survey responses demonstrated $80 \%$ of male caregivers lived with their child full-time and over one quarter primarily spoke Spanish at home (28\%) though only one SSI was conducted in Spanish as per caregiver comfort level and language preference. Sociodemographic characteristics of participants are shown in Table 1. All participating caregivers self-identified as trained central caregiver for the CYSHCN.

\section{Qualitative Results}

Broad themes identified within the qualitative data included unmet needs of male caregivers, interest in supportive resources, and advice to male caregivers.

\section{Unmet Needs of Male Caregivers}

Frequently unmet emotional, mental, or physical health needs of male caregivers emanated to fulfill the competing demands of work, family, and caregiving responsibilities of 
Table 1 Distribution of sociodemographic characteristics for all participants

\begin{tabular}{lll}
\hline Characteristic $(\mathrm{N}=30)$ & $\mathrm{N}$ (median) & $\%(\mathrm{IQR})$ \\
\hline Household living status & 24 & 80 \\
Lives with child full-time & 2 & 7 \\
Lives with child part-time & 4 & 13 \\
Do not live in same home as child & & \\
Language spoken at home $(\mathrm{N}=29)$ & 21 & 72 \\
English & 8 & 28 \\
Spanish & & \\
Household income $(\mathrm{N}=22)$ & 3 & 14 \\
$<\$ 15,000$ & 9 & 41 \\
\$15,000-\$29,999 & 4 & 18 \\
\$30,000-\$44,999 & 3 & 14 \\
\$45,000-\$59,999 & 3 & 14 \\
$\$ 75,000-\$ 99,999$ & $(41)$ & $(33,44)$ \\
Age & & \\
Race $(\mathrm{N}=29)$ & 1 & 3 \\
Asian & 9 & 31 \\
Black or African American & 1 & 3 \\
Native Hawaiian or other Pacific Islander & 7 & 24 \\
White & 11 & 38 \\
Other & 13 & 46 \\
Ethnicity $(\mathrm{N}=28)$ & 15 & 54 \\
Hispanic or Latino & & \\
Non-Hispanic or Latino & & \\
\hline
\end{tabular}

CYSHCN. Several respondents desired meeting personal educational goals and spending time alone with spouses/ additional children. Numerous co-occurring roles described by male caregivers included acting as parent, advocate, protector, financial provider, nurse, and care coordinator.

[W] hen he gets home, I give him lunch, change him...I put him to nap from 12:30 to $2 \mathrm{pm}$. At $2 \mathrm{pm}$ I get them dressed...take him and other kids out...\#7

.... He has all night care [g-tube/ventilator], we both work, and we have to be up with him it makes it very difficult when there's call outs [nursing] sometimes they'll come and sometimes not...\#3

[I]t's very stressful...she [Mom] has him all day at home, and then I come home from work tired because I sit in front of a computer all day...then I come home, she wants to give him to me... and I'm tired from work, so I just have to make it work...\#19

...when I make all of those appointments, I try to do all of them at the same time....\#15

The multiplicity male caregiver roles compared to time and resources available to fulfill role-related demands frequently strain themselves and co-parents. Male caregivers typically described a hierarchical approach to need fulfillment placing personal needs last, after the needs of their CYSHCN and co-parent.

...I. have learned....it's really important to really talk about things and not bottle things up.. \#5

...[Y]ou leave in the morning, go to work, then you have a horrible day in your job, you want to come home to have a break, and then your wife had a pretty rough day with [child] that you left her in the morning with the sleeping clothes, you get back in the afternoon.....and she's waiting for you to take a break... you go home to take a break and you have somebody there...expecting for you to be there for her to take a break so it continues like a constant movement mentally and physically... work and then the child at home with all the conditions...he doesn't sleep...so it was almost like 24/7 every day.\#16

Most male caregivers articulated a 'need for a break' as a parent, their spouse, or family unit. Finding and maintaining quality nursing care was essential in allowing families to have a break alleviating parental physical and emotional exhaustion.

Doing her[child's] stuff in the morning probably takes 45 minutes-hour.... you're really cooking by the time you're finished doing that. You're exhausted and the day just started...it's exhausting....The emotional drain makes the physical drain more tiring...you're physically tired, but I don't know if you're actually truly as physically tired as you are emotionally. Emotions make you feel physically drained. \#23

Most caregivers sought time and safe spaces for reflection on experiences and feelings. However, several hinted at contrasting gender-based expectations and ascribed to perceptions of needing to 'be the strong one' in the family, assigning themselves to familial roles of tactical/logistical planning. Many indicated abilities to restrict outwardly showing emotion reinforcing critical qualities of strength and maintenance of perceived emotional calm. One participant blamed himself for his child's long-term hospital stay, explaining it as a result of 'letting their guard down'.

For me, it's just...being a dad, being 'the man of the house' you have to be kind of the strong one. Try not to show much emotion in front of the girls...especially in the beginning. \#27

Another Explained:

I feel included due to my temperament and my calmness...I'll be the one that comes to the emergency room. [child's] mom, she says, "I might get a little too emotional, so I'd rather you go, at least you'll be clear and be able to say everything". You 
deal with your emotions later but you're able to stay focused until everything is fine and clear.\#18

Despite this internal tension, male caregivers articulated needs to improve their own emotional health/wellbeing. Expressing needs for personal privacy away from in-home care nursing/staff, they sought alone time and nurturing their spouses/co-parent relationships.

...the other day, I stood with him [child] in the house and she [wife] went to her mother's house...have a little talk with her...sometimes...we as parents need that. We need time for ourselves as well, and sometimes it's hard, because we're always with our child always at appointments. We have to work....it's really tough.\#24

Parental physical/mental health care improvement was hindered by competing responsibilities and lack of residual time/energy, ultimately negatively influencing their relationships with spouses/others and overall wellbeing.

\section{Interest in Supportive Resources}

Most participants expressed an interest in support groups, yet many felt lack of available time would ultimately limit their involvement. While several male caregivers indicated somewhat negative perceptions of support groups in a 'circle of chairs' setting, the majority were interested in support groups providing a healthy emotional space consistent with their needs/abilities to contribute their knowledge/ experiences.

I would have interest... some of my constraints are... time, energy, it would have to be the right group that meets the needs of my real life, and I think that would be tough to do. I would want it to work both ways, if it's a support group I would want to be able to offer support as well as receive support for myself. \#28

For those not interested in a formal support groups, many desired to give advice, share ideas/resources, build camaraderie among male caregivers of CYSHCN, participate in recreational opportunities, and obtain information about community services.

It might just be more to find some friends...it would be nice to talk to somebody who knows what you're going through. I have some friends who can empathize, but unless people are doing the same thing you are doing, they cannot relate...the next thing is time, you work a full day, come home, you want to spend time with [your child]....weekends I got [stuff] around the house I got to get to.\#11

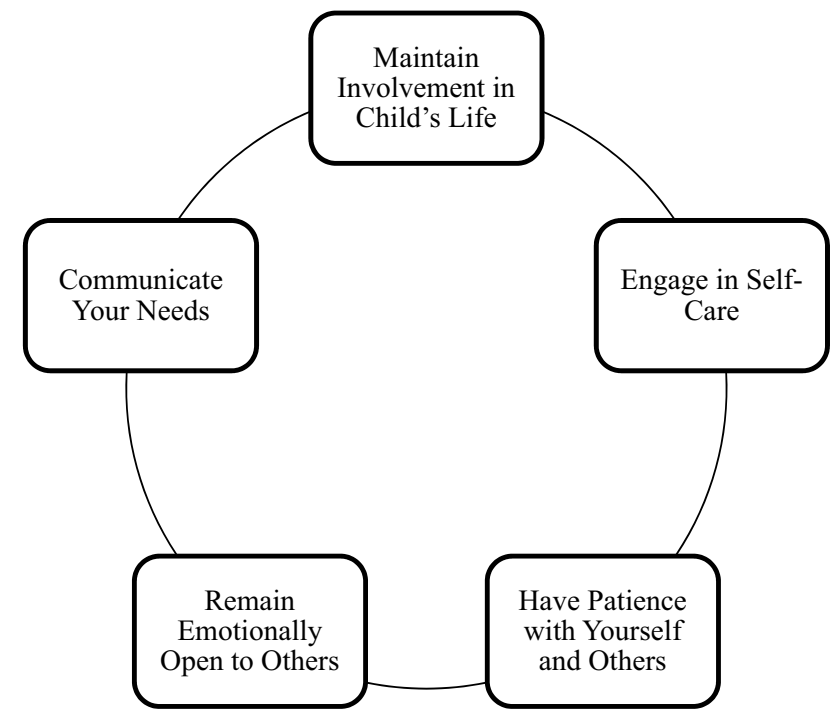

Fig. 1 Advice to other male caregivers regarding parenting CYSHCN

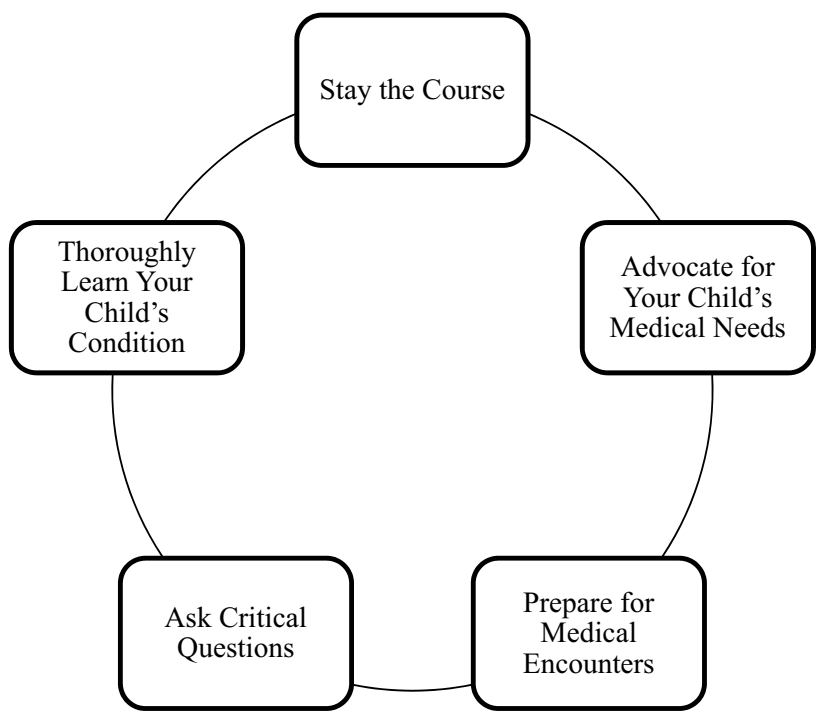

Fig. 2 Advice to other male caregivers regarding health care system navigation

\section{Advice to Male Caregivers: Parenting and Health Care System Navigation}

Heartfelt advice to other male caregivers focuses on general parenting strategies (Fig. 1) and approaches to navigating the health care system (Fig. 2).

Male caregivers were well-versed in their child's medical, social/emotional needs and logistics to support their child. They recommended other male caregivers strive for constant involvement in their child's life, commit to personal self-care, pursue emotional openness/communication 
with spouses/supportive individuals continuously working through challenging situations.

Stay involved and stay the course...it's going to get rough...it can get overwhelming...I know obviously us [men]...tend to deal with the task, push our emotions to the side, and sometimes we don't even deal with the emotion. Just make sure you take that time and be vulnerable if that's what you're feeling. It's ok for you to be upset, frustrated. We all know the battles we have due to our medically fragile child so, just stay the course. \#21

They encouraged others to develop an attitude of patience with oneself, their child, and their atypical family situation.

It's all about being patient, honestly, and just taking it one day at a time, you don't have to worry about tomorrow, tomorrow is not guaranteed, tomorrow is not promised, worry about now, right now, what's going on now, and you'll be fine. \#12

The collective advice on navigating the healthcare system was to stay the course with their CYSHCN advocating for their needs within the system and become independent experts in their child's specific medical condition, treatment needs, and responses to medications/behavioral therapies. Many indicated despite initial doubts/difficulties, quickly learned care for their CYSHCN with persistent involvement aiding in the success of their child.

Everything we do is a result it...has to do with our kids, and we see the results...if I would have decided to stay in my town, I would have never seen the results I have seen. Everything that one does with love gives fruit. \#29

\section{Discussion}

There is a dearth of literature focusing specifically on the unique needs of male caregivers of medically fragile CYSHCN. Prior qualitative studies underscore similar themes to this study such as consuming requirements/sacrifice of caring for CYSHCN, importance of trust of the medical system, caregiver stress burden, role of community supports, but do not delineate male caregivers' perspectives (Brodie et al., 2019; Mattson et al., 2019; Wood et al., 2009). In this study, several consistent themes emerged including unmet needs, supportive resource interests, and advice to other male caregivers. This information contributes to sparse research documenting the needs of male caregivers of CYSHCN. Participants exhibited a collective awareness of their unmet emotional, mental, and physical health needs and were open to receiving emotionally supportive resources providing a connection to other male caregivers of CYSHCN. Male caregivers articulated a high-stress burden resulting from caring for their CYSHCN but advised other male caregivers to remain involved. Encouraging fellow caregivers, they advised having self-compassion and preparation and proactivity on behalf of their child in medical settings, consistent with findings from prior studies (Neff \& Faso, 2015; Rafferty \& Sullivan, 2017).

The sustained negative mental/physical health consequences described by parents of CYSHCN are widely documented influencing family functioning, coping ability, life satisfaction, and ability to navigate challenges (Cousino \& Hazen, 2013; Darling et al., 2012; Goudie et al., 2014; Woodgate et al., 2015). Our analysis is consistent with this research detailing the mental/physical consequences of persistent stress and hidden emotional experiences of male caregivers (Caicedo, 2014; Edelstein et al., 2017; Heaman, 1995; Kvarme et al., 2016). As several male caregivers in our sample deprioritized some of their own needs, their voices support the need to include parental mental/emotional health within family-centered care models for CYSHCN (Donley et al., 2018; Thurston et al., 2011).

Male caregivers in our sample were open to receiving emotional/mental support in formats compatible with their lifestyles/goals. Their positive parenting attitudes were reflected in their encouraging advice to other parents of CYSHCN. Recognizing and understanding the stress and experiences of caregivers of CYSHCN reinforces needs for stronger linkages to resources for children and parents, including respite services, in-home supports and stress mitigating program opportunities. Most male caregivers saw value in support groups and resources specifically geared to male caregivers fostering opportunities to share similar lived experiences in safe spaces. Recommendations based on the themes from this study are summarized in Table 2.

Prior studies described challenges and unmet needs of families of CYSHCN including financial burden, stress, time constraints, and service access (Jolles et al., 2018; Kuo et al., 2011). Supportive solutions considerate of lack of residual time/energy indicated by our sample include parent training, formal support groups (e.g. group therapy) and informal supports (e.g. mentoring, planned social experiences) possibly facilitating camaraderie among male caregivers of CYSHCN (Ainbinder et al., 1998; Feudtner, 2002; Kerstis et al., 2018; Kobylianskii et al., 2018; Nicholas et al., 2016; Solomon et al., 2001). Programs should consider potential barriers such as possible caregiver adherence to a 'strong man' identity, possibly mediating his openness to receiving emotional support from others (Baldwin et al., 2018; Tully et al., 2017). Our results suggest programs focused on problem-solving, developing strategies to maintain perceived self-control (process-driven thinking), and focus on analyzing immediate problems could be useful design 
Table 2 Recommendations based on themes identified

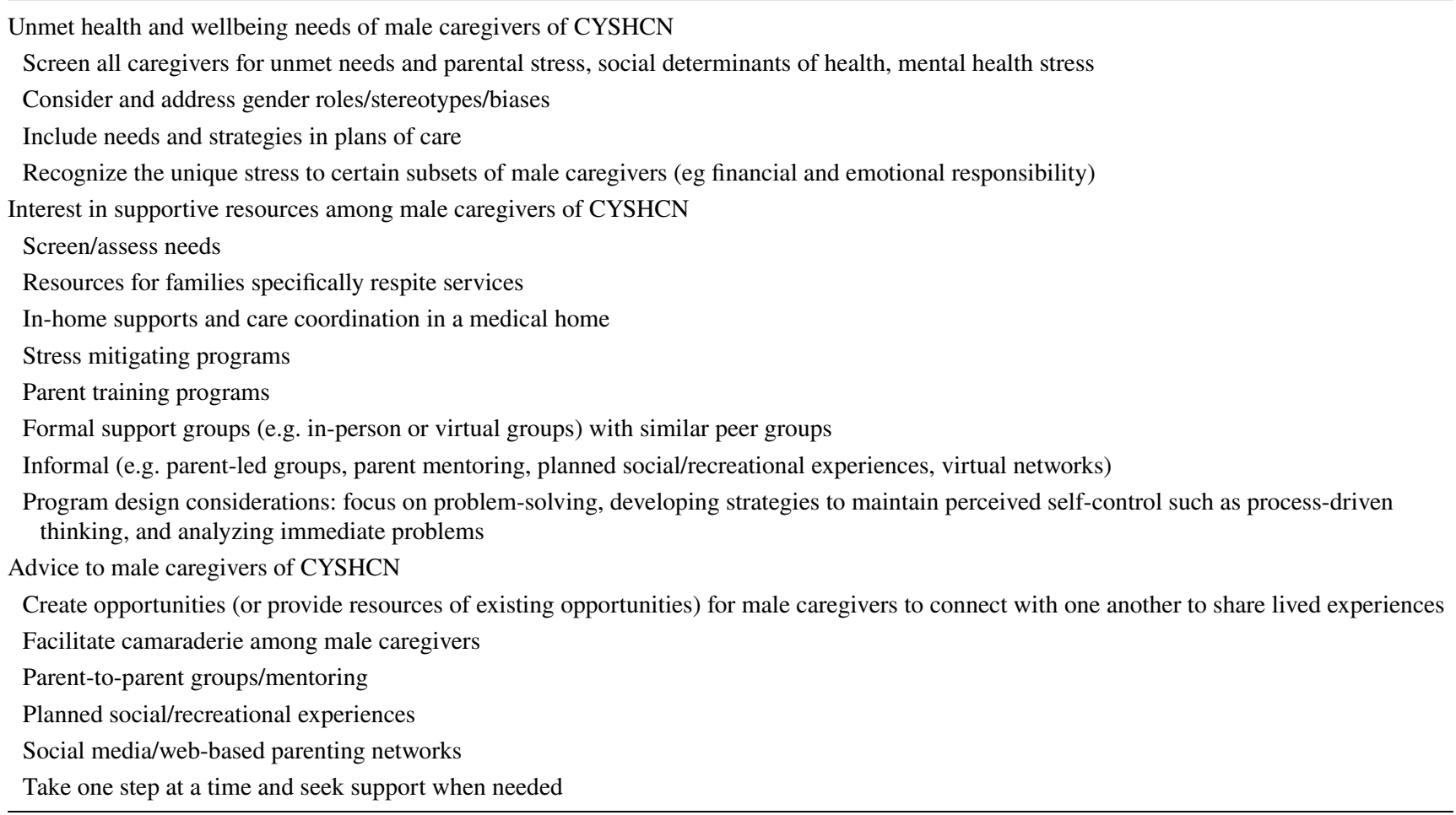

considerations. Parent-led support groups/mentoring programs for parents of CYSHCN have been effective in aiding parents to develop skills, sense of power/belonging, and provide welcome sources of emotional support among sameness of experience (Ainbinder et al., 1998; Kingsnorth et al., 2011; Law et al., 2002; Singer et al., 1999). Non-traditional formats for mentoring (social media, internet-based options) may be contextually fitting and have previously been effective (DeHoff et al., 2016). Prior studies described challenges for primary care/community partners caring for CYSHCN and may consider screening for parental stress/adequate supports and engaging families in shared plans of care (Disabilities, 2005; McAllister, 2014; Nageswaran, 2009).

\section{Limitations}

Qualitative inquiry is not generalizable by design. Assertions from these data should be interpreted accordingly. Almost half of the sample identifies as Hispanic and one respondent chose to conduct their interview in Spanish. Respondents were male caregivers of CYSHCN, however the interviewer was a young, educated, female without children and the degree of perceived dissimilarity between the respondents/ interviewer may have stymied sharing. Participants were all engaged in their child's medical care, therefore this analysis does not speak to the experiences/desires of men less engaged in the care. Understanding specific experiences of male caregivers not engaged in care could yield information to better support families before a male caregiver may become estranged from their CYSHCN. The concordance of dyads of caregivers when two or more caregivers are present warrants further exploration for the impact on partnerships, marriages, and relationships between caregivers of CYSHCN and siblings. Implementors may consider nontraditional formats for establishing connection and camaraderie among male caregivers.

\section{Conclusion}

Health care systems and medical care teams should foster the support and inclusion of male caregivers as significant members of CYSHCN care teams to further promote family centered care and shared decision making. Male caregivers of CYSHCN strongly desire emotionally supportive resources consistent with their lifestyles/family needs as unique and contributory members of their CYSHCN life and care continuum.

\section{Appendix}

\section{Sample Interview Guide}

Tell me a little bit about your [son/daughter]. 
- If father has not yet shared, ask about his child's diagnosis

How has it been understanding and coping with your child's medical condition?

What is the day-to-day care of your child like?

Are there barriers that you face in the day-to-day care?

How do you feel included in your child's care at home?

How do you feel included in your child's care at school?

How do you feel included in your child's care during medical appointments, or when [he/she] is in the hospital?

- How do you feel that the doctors and medical staff listen to you and value your input?

- [If not already mentioned] are there any circumstances when you feel excluded from your child's care?

Do you coordinate any of your child's medical care?

- [If, no] Who coordinate's your child's medical care?

- [If yes] About how much time per week do you spend coordinating your child's medical care?

- Do you share this responsibility with your child's mom? Other family member? Doctor's office?

I am going to list some services, can you let me know which ones do you already have, and which ones you don't have, but might find helpful?

\begin{tabular}{lll}
\hline Services & Already have Do not have & Would \\
& find \\
& helpful
\end{tabular}

\section{Respite care}

Daycare

Parental support groups

Help with behavior problems

Help with financial informa-

tion

After-school childcare

Assistance with physical

household changes

Vocational counseling

Psychological counseling

Homemaker services

Recreational opportunities

Information about commu-

nity services

What keeps you strong or keeps you going? Do you have family or friends who support you when things get tough?

How does your role differ from [his/her] mother's role?

Tell me about any internet or social media tools you have used to obtain resources for your child.
- For example, Facebook, Twitter, Tumbler, Pinterest, Instagram, Yahoo or Google group, reading/writing blogs or support group message board.

Would you have any interest in a support group for fathers of children with special needs?

- [If no] Would you prefer the group to include any caregiver of a child with special needs, or is a support group not something you are interested in joining?

Do you have any recommendations for your child's doctor office here [i.e. special needs] and or recommendations in general to help fathers?

Acknowledgements We would like to express our appreciation to all our participating families for whom we completed this work. We would also like to acknowledge John Kim, MPH, CPH who assisted in quantitative survey design and review of quantitative analysis. There are no funding acknowledgements.

Author contributions All authors are responsible for the reported research and have participated in the concept and design, analysis and interpretation of data, revisions, and have approved the manuscript as submitted.

Data Availability Authors have all data and study materials available for review in accordance with data procedures from IRB and human subjects protection guidelines.

Code Availability N-VIVO 12 was used for analyses in this study. (QSR International Pty Ltd., 2019).

\section{Declarations}

Conflict of interests The authors declare that they have no conflict of interests.

Ethics Approval This study was reviewed and approved by the Drexel University Institutional Review Board and was performed in accordance with Declaration of Helsinki ethical standards and amendments.

Consent to Participate Informed consent from study participants obtained in accordance with Drexel University Institutional Review Board and are available for review.

Consent for Publication The authors consent to publication of all materials submitted.

\section{References}

Ainbinder, J. G., Blanchard, L. W., Singer, G. H. S., Sullivan, M. E., Powers, L. K., Marquis, J. G., Santelli, B., \& Consortium to Evaluate Parent to Parent (1998). A qualitative study of parent to parent support for parents of children with special needs. Journal of Pediatric Psychology, 23(2), 99-109. https://doi.org/10.1093/ jpepsy/23.2.99

Bailey-Pearce, O., Stedmon, J., Dallos, R., \& Davis, G. (2018). Fathers' experiences of their child's life-limiting condition: An attachment narrative perspective. Clinical Child Psychology and Psychiatry, 23(3), 381-397. 
Baker, E. A., DeLuca Bishop, H., Stigall, L. A., \& van Dulmen, M. H. (2018). Positive parental engagement: Investigating the role of the mother-father relationship. Journal of Family Psychology, 32(8), 1005.

Baldwin, S., Malone, M., Sandall, J., \& Bick, D. (2018). Mental health and wellbeing during the transition to fatherhood: A systematic review of first time fathers' experiences. JBI Database of Systematic Reviews and Implementation Reports, 16(11), 2118.

Brodie, N., Bernstein, B., McNesby, F., \& Turchi, R. M. (2019). Perspectives of Latina mom's of children with special health care needs. Global Pediatric Health, 6, 1-7.

Caicedo, C. (2014). Families with special needs children: Family health, functioning, and care burden. Journal of the American Psychiatric Nurses Association, 20(6), 398-407.

Cené, C. W., Johnson, B. H., Wells, N., Baker, B., Davis, R., \& Turchi, R. (2016). A narrative review of patient and family engagement: The "foundation" of the medical home. Medical Care, 54(7), 697.

Chung, P. J., Lui, C. K., Cowgill, B. O., Hoffman, G., Elijah, J., \& Schuster, M. A. (2012). Employment, family leave, and parents of newborns or seriously ill children. Academic Pediatrics, 12(3), 181-188. https://doi.org/10.1016/j.acap.2012.02.001

Cohen, E., Kuo, D. Z., Agrawal, R., Berry, J. G., Bhagat, S. K., Simon, T. D., \& Srivastava, R. (2011). Children with medical complexity: An emerging population for clinical and research initiatives. Pediatrics, 127(3), 529.

Cousino, M. K., \& Hazen, R. A. (2013). Parenting stress among caregivers of children with chronic illness: A systematic review. Journal of Pediatric Psychology, 38(8), 809-828. https://doi.org/ 10.1093/jpepsy/jst049

Darling, C. A., Senatore, N., \& Strachan, J. (2012). Fathers of children with disabilities: Stress and life satisfaction. Stress and Health, 28(4), 269-278.

Data Resource Center (DRC) for Child and Adolescent Health. (2016) National Survey of Children's Health (NSCH) Data Query. Child and Adolescent Health Measurement Initiative. Retrieved August 26, 2016, from https://www.childhealthdata.org/browse/survey/ results? $\mathrm{q}=4562 \& \mathrm{r}=1$.

DeHoff, B. A., Staten, L. K., Rodgers, R. C., \& Denne, S. C. (2016). The role of online social support in supporting and educating parents of young children with special health care needs in the United States: A scoping review. Journal of Medical Internet Research, 18(12), e333. https://doi.org/10.2196/jmir.6722

Disabilities,Council on Children With. (2005). Care coordination in the medical home: Integrating health and related systems of care for children with special health care needs. Pediatrics, 116, 1238-1244. https://doi.org/10.1542/peds.2005-2070

Donley, T., King, D. M., Nyathi, N., Okafor, A., \& Mbizo, J. (2018). Socioeconomic status, family functioning and delayed care among children with special needs. Social Work in Public Health, 33(6), 366-381.

Edelstein, H., Schippke, J., Sheffe, S., \& Kingsnorth, S. (2017). Children with medical complexity: A scoping review of interventions to support caregiver stress. Child: Care, Health and Development, 43(3), 323-333. https://doi.org/10.1111/cch.12430

Feudtner, C. (2002). Grief-love: Contradictions in the lives of fathers of children with disabilities. Archives of Pediatrics \& Adolescent Medicine, 156(7), 643-643.

Goudie, A., Narcisse, M.-R., Hall, D. E., \& Kuo, D. Z. (2014). Financial and psychological stressors associated with caring for children with disability. Families, Systems \& Health: Journal of Collaborative Family Healthcare, 32(3), 280-290. https://doi.org/10.1037/ fsh0000027

Hatzmann, J., Heymans, H. S., Ferrer-i-Carbonell, A., van Praag, B. M., \& Grootenhuis, M. A. (2008). Hidden consequences of success in pediatrics: Parental health-related quality of life-results from the Care Project. Pediatrics, 122(5), e1030-1038. https:// doi.org/10.1542/peds.2008-0582

Heaman, D. J. (1995). Perceived stressors and coping strategies of parents who have children with developmental disabilities: A comparison of mothers with fathers. Journal of Pediatric Nursing, 10(5), 311-320. https://doi.org/10.1016/S0882-5963(05)80049-1

Inc., S. I. (2019). SAS 9.4. https://www.sas.com/en_us/home.html.

Jolles, M. P., Lee, P. J., \& Javier, J. R. (2018). Shared decision-making and parental experiences with health services to meet their child's special health care needs: Racial and ethnic disparities. Patient Education and Counseling, 101(10), 1753-1760. https://doi.org/ 10.1016/j.pec.2018.05.022

Keller, D., \& Honig, A. S. (2004). Maternal and paternal stress in families with school-aged children with disabilities. American Journal of Orthopsychiatry, 74(3), 337-348. https://doi.org/10. 1037/0002-9432.74.3.337

Kerstis, B., Wells, M. B., \& Andersson, E. (2018). Father group leaders' experiences of creating an arena for father support: A qualitative study. Scandinavian Journal of Caring Sciences, 32(2), 943-950.

Kingsnorth, S., Gall, C., Beayni, S., \& Rigby, P. (2011). Parents as transition experts? Qualitative findings from a pilot parent-led peer support group. Child: Care, Health and Development, 37(6), 833-840. https://doi.org/10.1111/j.1365-2214.2011.01294.x

Kobylianskii, A., Jegathesan, T., Young, E., Fung, K., Huber, J., \& Minhas, R. S. (2018). Experiences of inner-city fathers of children with chronic illness. Clinical Pediatrics, 57(7), 792-801.

Kuo, D., Cohen, E., Agrawal, R., Berry, J. G., \& Casey, P. H. (2011). A national profile of caregiver challenges among more medically complex children with special health care needs. Archives of Pediatrics \& Adolescent Medicine, 165(11), 1020.

Kvarme, L. G., Albertini-Früh, E., Brekke, I., Gardsjord, R., Halvorsrud, L., \& Liden, H. (2016). On duty all the time: Health and quality of life among immigrant parents caring for a child with complex health needs. Journal of Clinical Nursing, 25(3-4), 362-371.

Law, M., King, S., Stewart, D., \& King, G. (2002). The perceived effects of parent-led support groups for parents of children with disabilities. Physical \& Occupational Therapy in Pediatrics, 21(2-3), 29-48. https://doi.org/10.1080/J006v21n02_03

Logan, R. M., \& Dormire, S. (2018). Finding my way: A phenomenology of fathering in the NICU. Advances in Neonatal Care, 18(2), 154-162.

Mattson, G., Kuo, D. Z., \& Committee on Psychosocial Aspects of Child and Family Health and Council on Children with Disabilities. (2019). Psychosocial factors in children and youth with special health care needs and their families. Pediatrics, $143,1$.

McAllister, J. (2014). Achieving a shared plan of care with children and youth with special health care needs. Lucile Packard Foundation for Children's Health. Retrieved August 26, 2016, from https://www.lpfch.org/publication/achieving-shared-plan-carechildren-and-youth-special-health-care-needs.

McPherson, M., Arango, P., Fox, H., Lauver, C., McManus, M., Newacheck, P. W., Perrin, J. M., Shonkoff, J. P., \& Strickland, B. (1998). A new definition of children with special health care needs. Pediatrics, 102(1), 137-139.

Mohanty, S., Wells, N., Antonelli, R. A., \& Turchi, R. M. (2018). Incorporating patient and family centered care into practice: The PA medical home initiative. Pediatrics, 142, 3. https://doi.org/10. 1542/peds.2017-2453

Nageswaran, S. (2009). Respite care for children with special health care needs. Archives of Pediatrics and Adolescent Medicine, 163(1), 49-54. https://doi.org/10.1001/archpediatrics.2008.504

Neff, K. D., \& Faso, D. J. (2015). Self-compassion and well-being in parents of children with autism. Mindfulness, 6(4), 938-947. https://doi.org/10.1007/s12671-014-0359-2 
Nicholas, D. B. (2017). Examining the roles and experiences of fathers of children with chronic kidney disease. Global Qualitative Nursing Research, 4, 1-8. https://doi.org/10.1177/2333393617705035

Nicholas, D. B., Beaune, L., Barrera, M., Blumberg, J., \& Belletrutti, M. (2016). Examining the experiences of fathers of children with a life-limiting illness. Journal of Social Work in End-of-Life \& Palliative Care, 12(1-2), 126-144.

Patton, M. Q. (2005). Qualitative research. In Encyclopedia of statistics in behavioral science.

QSR International Pty Ltd. (2019). Nivo 12 (Version 12). https://www. qsrinternational.com/nvivo/nvivo-products.

Rafferty, K. A., \& Sullivan, S. L. (2017). "You know the medicine, I know my kid": How parents advocate for their children living with complex chronic conditions. Health Communication, 32(9), 1151-1160. https://doi.org/10.1080/10410236.2016.1214221

Sato, M., Oshitani, H., Tamaki, R., Oyamada, N., Sato, K., Nadra, A. R., Landicho, J., Alday, P. P., Lupisan, S., \& Tallo, V.L. (2018). Father's roles and perspectives on healthcare seeking for children with pneumonia: Findings of a qualitative study in a rural community of the Philippines. British Medical Journal Open, 8(11), e023857.

Sellmaier, C. (2019). Work, family, and community ecologies and their influence on work-life fit for fathers of children with special health care needs. Families in Society, 100(1), 68-79.

Singer, G. H., Marquis, J., Powers, L. K., Blanchard, L., Divenere, N., Santelli, B., Ainbinder, J. G., \& Sharp, M (1999). A multi-site evaluation of parent to parent programs for parents of children with disabilities. Journal of Early Intervention, 22(3), 217-229. https://doi.org/10.1177/105381519902200305

Smith, A. M., \& Grzywacz, J. G. (2014). Health and well-being in midlife parents of children with special health needs. Families, Systems \& Health, 32(3), 303.
Solomon, M., Pistrang, N., \& Barker, C. (2001). The benefits of mutual support groups for parents of children with disabilities. American Journal of Community Psychology, 29(1), 113-132. https://doi. org/10.1023/a:1005253514140

Thurston, S., Paul, L., Loney, P., Ye, C., Wong, M., \& Browne, G. (2011). Associations and costs of parental symptoms of psychiatric distress in a multi-diagnosis group of children with special needs. Journal of Intellectual Disability Research, 55(3), 263280. https://doi.org/10.1111/j.1365-2788.2010.01356.x

Tully, L. A., Piotrowska, P. J., Collins, D. A., Mairet, K. S., Black, N., Kimonis, E. R., Hawes, D. J., Moul, C., Lenroot, R. K., Frick, P. J., \& Anderson, V. (2017). Optimising child outcomes from parenting interventions: Fathers' experiences, preferences and barriers to participation. BMC Public Health, 17(1), 550.

Warfield, M. E. (2005). Family and work predictors of parenting role stress among two-earner families of children with disabilities. Infant and Child Development: An International Journal of Research and Practice, 14(2), 155-176.

Wood, D. L., McCaskill, Q. E., Winterbauer, N., Jobli, E., Hou, T., Wludyka, P., Stowers, K., \& Livingood, W. (2009). A multimethod assessment of satisfaction with services in the medical home by parents of children and youth with special health care needs (CYSHCN). Maternal and Child Health Journal, 13, 5-17.

Woodgate, R. L., Edwards, M., Ripat, J. D., Borton, B., \& Rempel, G. (2015). Intense parenting: A qualitative study detailing the experiences of parenting children with complex care needs. $B M C$ Pediatrics, 15, 197. https://doi.org/10.1186/s12887-015-0514-5

Publisher's Note Springer Nature remains neutral with regard to jurisdictional claims in published maps and institutional affiliations. 